\title{
Dietary intake of nitrate and nitrite and risk of renal cell carcinoma in the NIH-AARP Diet and Health Study
}

\author{
C T DellaValle ${ }^{*, 1}$, C R Daniel ${ }^{2}$, B Aschebrook-Kilfoy ${ }^{3}$, A R Hollenbeck ${ }^{4}$, A J Cross ${ }^{2}$, R Sinha ${ }^{2}$ and M H Ward ${ }^{1}$ \\ ${ }^{1}$ Department of Health and Human Services, Occupational and Environmental Epidemiology Branch, Division of Cancer \\ Epidemiology and Genetics, National Cancer Institute, National Institutes of Health, NIH/DHHS, 6120 Executive Boulevard, EPS \\ 8011, Bethesda, Rockville, MD 20892, USA; ${ }^{2}$ Department of Health and Human Services, Nutritional Epidemiology Branch, Division \\ of Cancer Epidemiology and Genetics, National Cancer Institute, National Institutes of Health, Rockville, MD 20892, USA; \\ ${ }^{3}$ Department of Health Studies, University of Chicago, Chicago, IL, USA and ${ }^{4}$ AARP, Washington, DC, USA
}

Background: Nitrate and nitrite are present in many foods and are precursors of $\mathrm{N}$-nitroso compounds, known animal carcinogens and potential human carcinogens. We prospectively investigated the association between nitrate and nitrite intake from dietary sources and risk of renal cell carcinoma (RCC) overall and clear cell and papillary histological subtypes in the NIH-AARP Diet and Health Study.

Methods: Nitrate and nitrite intakes were estimated from a 124-item food frequency questionnaire. Over a mean follow-up of 9 years, we identified 1816 RCC cases $(n=498$, clear cell; $n=115$, papillary cell) among 491841 participants. Cox proportional hazard regression was used to estimate hazard ratios (HRs) and 95\% confidence intervals (Cls).

Results: Individuals in the highest quintile of nitrite intake from animal sources compared with those in the lowest quintile, had an increased risk of total $\mathrm{RCC}$ and clear cell subtype $(\mathrm{HR}=1.28,95 \% \mathrm{Cl}, 1.10-1.49$ and $\mathrm{HR}=1.68,95 \% \mathrm{Cl}, 1.25-2.27$, respectively). Nitrite from processed meats and other animal sources were associated with increased clear cell adenocarcinoma risk $(H R=1.33$, $95 \% \mathrm{Cl}, 1.01-1.76$ and $\mathrm{HR}=1.78,95 \% \mathrm{Cl}, 1.34-2.36$, respectively). We found no association for nitrite intake from plant sources or nitrate intake overall.

Conclusion: Our findings suggest that nitrite from animal sources may increase the risk of RCC, particularly clear cell adenocarcinomas.

Renal cell carcinomas (RCCs), adenocarcinomas of the renal parenchyma, comprise more than $90 \%$ of adult kidney cancers in the United States (Horner et al, 2009; Chow et al, 2010). There are several histological variants of RCC, the majority of which are of the clear cell subtype, followed by RCC not otherwise specified, papillary and chromophobe subtypes (Chow et al, 2010). From 1977 to 2006, the incidence of RCC in the United States has steadily increased (Horner et al, 2009). Well-established risk factors include cigarette smoking, obesity and hypertension. However, these risk factors only explain $\sim 50 \%$ of RCC incidence
(Chow et al, 1999; Moore et al, 2005). Thus, there are likely unidentified factors, including, but not limited to environmental and dietary exposures that deserve further study.

Inorganic nitrate $\left(\mathrm{NO}_{3}^{-}\right)$is a naturally occurring compound in plants and can be found in high concentrations in certain dark green, leafy and root vegetables (Gangolli et al, 1994; IARC, 2010). Ingested nitrate can be reduced to nitrite $\left(\mathrm{NO}_{2}^{-}\right)$by bacteria present in the digestive system. Nitrite is also found in several foods, especially processed meats, where nitrite and nitrate salts are added as preservatives and to enhance colour and flavour 
(McKnight et al, 1999). Endogenous nitrosation, which is estimated to contribute $\sim 40-75 \%$ of total human exposure to $N$-nitroso compounds (NOC) (Tricker, 1997), occurs when nitrite reacts with other nitrosation precursors, mainly amines and amides, to form NOCs, which have been observed to induce tumours of the kidney in animals (IARC, 1998). Although carcinogenic evidence in humans is limited (IARC, 1998; McKnight et al, 1999; Ward et al, 2005), exposure to NOCs is a biologically plausible (Bogovski \& Bogovski, 1981; Hard, 1998; IARC, 2010), though poorly studied, mechanism for RCC development.

Epidemiological evidence for dietary risk factors associated with RCC risk, including intakes of nitrate and nitrite, is limited. In one population-based case-control study, intake of nitrate in drinking water was positively associated with RCC risk among individuals with low vitamin $\mathrm{C}$ or high red meat intakes; however, nitrate from diet was inversely associated with RCC risk (Ward et al, 2007). These findings are in agreement with evidence that vitamin $\mathrm{C}$ inhibits endogenous nitrosation (Mirvish, 1994) and red meat contains amines and amides, which are nitrosation precursors and may enhance NOC formation (IARC, 2010). The few studies of dietary nitrite and RCC have not found significant associations with risk (Yuan et al, 1998; Ali et al, 2003; Ward et al, 2007). However, these studies did not explore intakes of nitrate or nitrite by food source or by intake levels of NOC inhibitors or precursors. Further, they did not investigate RCC by histological subtype. A recent study of a subcohort within the NIH-AARP Diet and Health Study of individuals who completed a detailed questionnaire on meat-cooking methods and doneness levels found an increased risk of RCC associated with red meat intake, which is related to endogenous formation of potentially carcinogenic NOCs, and a two-fold increased risk of papillary RCC specifically (Daniel et al, 2012). Although the authors did not observe an association between intake of nitrate and nitrite from processed meat sources (Daniel et al, 2012), we expanded the previous analysis of the subcohort within the NIH-AARP Diet and Health Study to include a more comprehensive prospective investigation of nitrite and nitrate intake from a variety of dietary sources in relation to RCC risk. Within the large, prospective NIH-AARP Diet and Health Study, we further examined associations between nitrate and nitrite intake and clear cell as well as papillary RCC histological subtypes.

\section{MATERIALS AND METHODS}

Study population. The NIH-AARP Diet and Health Study is a prospective cohort of AARP (AARP was formerly known as the American Association of Retired Persons) members aged 50-71 years at enrolment residing in six US states (California, Florida, Louisiana, New Jersey, North Carolina, Pennsylvania) or two metropolitan areas (Atlanta, Georgia and Detroit, Michigan). In 1995-1996, a baseline questionnaire was mailed to participants. The questionnaire ascertained information on demographics and lifestyle as well as usual dietary and supplement intake over the 12 months before questionnaire completion. The cohort has been described in detail previously (Schatzkin et al, 2001). Within 6 months, participants who did not have self-reported cancer of the colon, breast or prostate at baseline were mailed a risk factor questionnaire, including additional medical history information. The NIH-AARP Diet and Health Study was approved by the Special Studies Institutional Review Board of the National Cancer Institute.

A total of 566399 participants completed the baseline questionnaire. For this analysis, we used the following exclusion criteria: participants whose questionnaire was filled out by a proxy respondent ( $n=15760)$, participants with prevalent cancer (except for nonmelanoma skin cancer; $n=51223$ ) or end-stage renal disease at baseline $(n=997)$, a mortality report only for any cancer $(n=2143)$, zero person-years of follow-up $(n=44)$, and total energy intake outside of two interquartile ranges above the $75^{\text {th }}$ or below the $25^{\text {th }}$ percentile $(n=4391)$. Exclusions for extreme total energy intake have been described in detail previously (Thompson et al, 2008). After exclusions, our analyses included 491841 participants (293248 men, 198593 women).

Case ascertainment. Renal cell carcinoma (RCC) cases were identified through 31 December 2006 via linkage with the eight original state cancer registries plus three additional states (Texas, Arizona and Nevada) where participants commonly migrated. The cancer registries are certified by the North American Association of Central Cancer Registries as being at least $90 \%$ complete within 2 years of cancer incidence. Ascertainment of cancer cases within the NIH-AARP Diet and Health study has been described in detail elsewhere (Michaud et al., 2005). Follow-up for each subject began on the date of questionnaire return and continued until the date of cancer diagnosis, date of censoring due to loss to follow-up, death or 31 December 2006, whichever came first.

Renal cell carcinoma (RCC) endpoints were defined by anatomic site and histological code using the International Classification of Diseases for Oncology, third edition (ICD-0-3) (World Health Organization, 2000). We restricted our definition of primary adenocarcinoma of the kidney (C649) to the following histology codes: $8140,8141,8190,8200,8211,8251,8255,8260$, $8270,8280,8310,8312,8316-8320,8323,8370,8440,8450,8480$, $8481,8490,8500,8504,8510,8521,8550,8570,8940,8959$. Clear cell (histology code 8310) and papillary (histology code 8260) adenocarcinomas (Eble et al., 2004), the two most common and distinctly defined histomorphological subtypes of RCC, were also evaluated separately.

Dietary assessment. The baseline questionnaire included a food frequency questionnaire (FFQ) that asked participants about their frequency of consumption and portion sizes of 124 food items over the prior 12 months. Intake of each item was assessed in 10 categories; 'never' to ' $2+$ times per day' for foods and 'never to ' $6+$ times per day' for beverages, and 3 portion size categories. The 1994-1996 US Department of Agriculture's Continuing Survey of Food Intakes by Individuals was used to calculate nutrient and total energy intake. The FFQ was developed and validated using two $24-\mathrm{h}$ recalls in a subset of the cohort by the National Cancer Institute (Thompson et al, 2008).

Concentrations of nitrate and nitrite for each food item were estimated from the existing body of scientific literature, as previously described (Ward et al, 2003, 2006; Kilfoy et al, 2011). Daily intake of nitrate and nitrite was calculated by multiplying the frequency of consumption of each food by the portion size and the nitrate and nitrite content of each food and summing across all food items. Nitrate and nitrite intake was calculated for animal and plant sources separately. In addition to examining nitrate and nitrite intake from all animal sources, we also calculated intake from processed meat sources separately as well as animal sources excluding processed meat, which primarily includes intake from fresh meats, eggs, yogurt, cheese and other dairy products.

The US Environmental Protection Agency has set a maximum contaminant level for public drinking water at $\geqslant 10 \mathrm{mg}$ nitrate per litre. We estimated the likelihood of exposure to elevated nitrate from drinking water ( $\geqslant 10 \mathrm{mg}$ nitrate per litre) based on the census tract location of a participant's residence at enrolment, as the usual source of drinking water was not ascertained for the cohort. The estimation of possible nitrate exposure from tap water has been described in detail previously (Kilfoy et al, 2011). Briefly, the proportion of each census tract with estimated nitrate concentrations $\geqslant 10 \mathrm{mgl}^{-1}$, as estimated from the United States Geological Society groundwater nitrate model, was calculated. Sensitivity analyses excluded participants who resided in census tracts where 
$\geqslant 50 \%$ of the area was predicted to have nitrate levels $\geqslant 10 \mathrm{mgl}^{-1}$ because at this level drinking water can be a major source of nitrate intake and may even exceeded intake from diet (Chilvers et al, 1984; Moller et al, 1989) ( $n=11210$ total study participants ( $n=47$ RCC cases; $n=23$ clear cell; $n=3$ papillary cell); $2.3 \%$ of the study population).

Statistical analysis. Cox proportional hazards regression models with person-years as the underlying time metric were used to estimate hazard ratios (HRs) and 95\% confidence intervals (CIs) for the association between RCC and quintiles of nitrate and nitrite intake. Nitrate and nitrite intake, as well as all other dietary variables, were adjusted for total energy intake and expressed as intake per $1000 \mathrm{kcal}$ using the nutrient density method (Willett, 1998). The proportional hazards assumption was tested and upheld in all analyses. All multivariable models were adjusted for age (modelled as a continuous covariate), gender, education $(<12$ years, high school graduate, some college, college graduate, missing/unknown), family history of any cancer (first-degree relative), race (non-Hispanic white, non-Hispanic black, other (Hispanic, Asian/Pacific Islander, American Indian/Alaskan Native or unknown)), body mass index $(<25,25$ to $<30,30$ to $<35$, $\geqslant 35 \mathrm{~kg} \mathrm{~m}^{-2}$, or unknown), smoking status (never, former $\leqslant 20$ cigarettes per day, former $>20$ cigarettes per day, current $\leqslant 20$ cigarettes per day, current $>20$ cigarettes per day, unknown), history of diabetes (yes, no), history of hypertension (yes, no) and alcohol intake (none, 0 to $<5,5$ to $<15,15$ to $<30$, $\geqslant 30$ g per day) and caloric intake.

Adjustment for physical activity, marital status, intakes of saturated fat, cholesterol, total fibre, trans-fatty acids and $\alpha$ linolenic acid as well as intakes of dietary and supplemental vitamin $\mathrm{C}$, vitamin $\mathrm{E}$, iron, calcium and beta carotene did not substantially change risk estimates and were therefore not included in final models. We investigated potential effect modification by factors known to affect endogenous formation of NOCs, including vitamin $\mathrm{C}$ and vitamin $\mathrm{E}$, by conducting stratified analyses using the median as the cutpoint (Mirvish, 1994). We also stratified analyses by potential RCC risk factors, including median intakes of total fat and calcium, BMI $(<30 / \geqslant 30)$, history of hypertension (yes/no), history of diabetes (yes/no), smoking (never/current/former), physical activity (above/below 3-4 times per week) and gender. Results of stratified analyses were confirmed by examining the interaction cross-product terms in multivariable models. We analysed females in models with and without additional adjustment for menopausal hormone therapy and parity and did not observe any substantial difference in risk estimates.

Tests for linear trend were conducted using the median value of each exposure category as a continuous variable in the model. All $P$-values were two-sided, $\alpha=0.05$ indicates statistical significance, and HRs and 95\% CIs were calculated using SAS statistical software version 9.1 (SAS Institute, Inc., Cary, NC, USA).

\section{RESULTS}

Over 4476075 years of follow-up (mean $=9.1$ years), a total of 1816 cases of RCC were identified ( $n=498$, clear cell; $n=115$, papillary cell) among 491841 participants. Characteristics of the cohort by quintiles of nitrate and nitrite intake are shown in Table 1. Compared with the lowest quintile of nitrate and nitrite intake, participants in the highest quintile of nitrate and nitrite intake were more likely to be never or former smokers; report a history of diabetes; and consume more white meat, fruits, and vegetables. Participants in the highest quintile of nitrate and nitrite intake consumed less alcohol, red meat, and fewer calories. Intake of processed meats was also lower among participants in the highest quintile of nitrate intake. As expected, participants in the highest quintile of nitrite intake consumed more processed meat than those in the lowest quintile of intake. Females tended to have higher intakes of dietary nitrate, whereas males had higher intakes of nitrite.

Daily mean dietary nitrate intake in the study population was $51.0 \mathrm{mg}$ per $1000 \mathrm{kcal}$ (s.d. $=36.3 \mathrm{mg}$ per $1000 \mathrm{kcal}$ ), which came almost entirely from plant sources (94.5\%). We present results for dietary nitrate intake overall because such a high proportion of dietary nitrate came from plant sources and risk estimates were similar when examining nitrate from plant and animal sources separately. Mean daily dietary nitrite intake was $0.7 \mathrm{mg}$ per $1000 \mathrm{kcal}$ (s.d. $=0.2 \mathrm{mg}$ per $1000 \mathrm{kcal}$ ). Nitrite from animal sources accounted for $33 \%$ of daily mean intake of nitrite $(0.2 \mathrm{mg}$ per $1000 \mathrm{kcal}$ ), with the remainder of nitrite intake derived from plant sources. Approximately $40 \%$ of nitrite from animal sources was derived from processed meats $(0.1 \mathrm{mg}$ per $1000 \mathrm{kcal})$. The daily average combined nitrate and nitrite intake from processed meat sources was $0.7 \mathrm{mg}$ per $1000 \mathrm{kcal}(\mathrm{SD}=0.7)$.

Associations between nitrate and nitrite intake and risk of RCC are shown in Table 2. Risk estimates among males and females were similar and the interaction between nitrate and nitrite intake and gender was not significant $(P$-interaction $=0.24$ and 0.79 , respectively), therefore, risk estimates are presented for men and women combined. We did not observe any significant associations between intake of nitrate and risk of total RCC or clear cell or papillary subtypes. We observed an increased risk of total RCC among participants in the highest quintile of nitrite from animal sources intake compared with those in the lowest quintile $(\mathrm{HR}=1.28,95 \% \mathrm{CI}, 1.10-1.49)$ with a significant positive trend $(P$-trend $<0.01)$. Similar associations were observed when nitrite from processed meat $(\mathrm{HR}=1.16,95 \% \mathrm{CI}, 1.00-1.35)$ and nitrite from other animal sources, excluding processed meat $(\mathrm{HR}=1.23,95 \% \mathrm{CI}, 1.06-1.43)$ were examined individually. In addition, participants in the highest quintile of nitrate and nitrite from processed meat sources were also found to have an increased risk of total RCC compared with participants in the lowest intake quintile $(\mathrm{HR}=1.17,95 \% \mathrm{CI}, 1.00-1.37)$. We did not observe any statistically significant associations between nitrite intake from plant sources or total nitrite intake and risk of total RCC.

Similar to the results for total RCC, increased risk of clear cell adenocarcinoma was observed in both the highest quintile of nitrite from animal sources $(\mathrm{HR}=1.68,95 \% \mathrm{CI}, 1.25-2.27)$ and processed meat $(\mathrm{HR}=1.33,95 \% \mathrm{CI}, 1.01-1.76)$, compared with the lowest quintiles of intake. Risk of the clear cell adenocarcinoma subtype was elevated with increasing intake of nitrate and nitrite from processed meats $(P$-trend $=0.01)$. Intake of nitrite overall also demonstrated an association with risk of clear cell adenocarcinoma $(\mathrm{HR}=1.34,95 \% \mathrm{CI}, 1.00-1.80)$. Plant sources of nitrite were not associated with risk of clear cell RCC. We also observed a decreased risk of papillary RCC among individuals in the highest quintile of nitrite from animal sources excluding processed meats $(\mathrm{HR}=0.43,95 \% \mathrm{CI}, 0.22-0.84)$, compared with the lowest quintile of intake. The direction of associations between intakes of nitrite from other sources and papillary RCC were inconsistent and not statistically significant (Table 2). In sensitivity analysis excluding participants potentially exposed to high levels of nitrate $\left(\geqslant 10 \mathrm{mgl}^{-1}\right)$ in their drinking water $(2.3 \%$ of the study population), risk estimates were similar to our main findings (results not shown).

We did not observe any effect modification by vitamin $\mathrm{C}$ or vitamin E. We also did not observe any differences by RCC risk factors, including intakes of total fat and calcium, BMI $(<30 /$ $\geqslant 30$ ), history of hypertension (yes/no), history of diabetes (yes/ no), smoking (never/former/current), and physical activity (above/ below 3-4 times per week) (results not shown). 
Table 1. Characteristics of the NIH-AARP Diet and Health Study cohort by density-adjusted quintiles of total nitrate and nitrite ( $\mathrm{g}$ per $1000 \mathrm{kcal})$ intake $(n=491841)$

\section{Quintiles of nitrate (median)}

Quintiles of nitrite (median)

\begin{tabular}{|l|c|c|c|c|r|r|r|r|}
\hline Characteristic & Q1 (19.3) & Q3 (40.9) & O5 (94.8) & Q1 (0.5) & Q3 (0.7) & Q5 (0.9) \\
\hline Gender (\%) & 74.7 & 60.5 & 42.0 & 65.1 & 59.6 & 54.5 \\
\hline Male & 25.3 & 39.5 & 58.0 & 34.9 & 40.4 & 45.5 \\
\hline
\end{tabular}

Race (\%)

\begin{tabular}{|c|c|c|c|c|c|c|}
\hline White & 90.9 & 92.0 & 90.1 & 92.0 & 92.4 & 87.3 \\
\hline Black & 3.9 & 3.6 & 4.3 & 4.5 & 3.6 & 4.1 \\
\hline Other & 3.7 & 3.3 & 4.1 & 2.1 & 2.8 & 7.0 \\
\hline Missing & 1.5 & 1.1 & 1.5 & 1.4 & 1.2 & 1.6 \\
\hline
\end{tabular}

\section{Education (\%)}

\begin{tabular}{|c|c|c|c|c|c|c|}
\hline$<12$ years & 32.2 & 24.3 & 21.4 & 26.3 & 25.4 & 25.1 \\
\hline High school graduate & 11.1 & 9.8 & 8.7 & 10.2 & 9.9 & 9.2 \\
\hline Some college & 22.6 & 23.0 & 24.2 & 24.6 & 22.7 & 22.6 \\
\hline College graduate & 31.1 & 40.1 & 42.6 & 36.0 & 39.2 & 39.8 \\
\hline Missing & 3.1 & 2.8 & 3.1 & 2.9 & 2.9 & 3.3 \\
\hline
\end{tabular}

\section{Family history of cancer (\%)}

\begin{tabular}{|c|c|c|c|c|c|c|}
\hline $\begin{array}{l}\text { No } \\
\text { Yes } \\
\text { Unknown/missing }\end{array}$ & $\begin{array}{r}46.9 \\
47.7 \\
5.4\end{array}$ & $\begin{array}{r}46.0 \\
48.8 \\
5.2\end{array}$ & $\begin{array}{r}45.9 \\
49.0 \\
5.1\end{array}$ & $\begin{array}{r}46.4 \\
48.4 \\
5.2\end{array}$ & $\begin{array}{r}45.7 \\
49.2 \\
5.1\end{array}$ & $\begin{array}{r}46.9 \\
47.7 \\
5.4\end{array}$ \\
\hline \multicolumn{7}{|l|}{ Smoking status (\%) } \\
\hline $\begin{array}{l}\text { Never } \\
\text { Former ( } \leqslant 20 \text { cigarettes per day) } \\
\text { Former }(20+\text { per day) } \\
\text { Current }(\leqslant 20 \text { per day }) \\
\text { Current }(20+\text { per day) } \\
\text { Unknown }\end{array}$ & $\begin{array}{r}29.6 \\
24.1 \\
23.5 \\
10.5 \\
8.3 \\
3.9\end{array}$ & $\begin{array}{r}36.8 \\
28.2 \\
21.0 \\
7.0 \\
3.3 \\
3.7\end{array}$ & $\begin{array}{r}37.5 \\
30.4 \\
19.6 \\
6.5 \\
2.0 \\
4.0\end{array}$ & $\begin{array}{r}28.0 \\
24.8 \\
23.9 \\
11.2 \\
8.2 \\
3.9\end{array}$ & $\begin{array}{r}36.3 \\
28.4 \\
21.0 \\
7.2 \\
3.5 \\
3.6\end{array}$ & $\begin{array}{r}39.3 \\
29.1 \\
20.1 \\
5.3 \\
2.1 \\
4.1\end{array}$ \\
\hline
\end{tabular}

\section{Ever diagnosed with hypertension (\%)}

\begin{tabular}{|c|c|c|c|c|c|c|}
\hline $\begin{array}{l}\text { No } \\
\text { Yes } \\
\text { Unknown/missing }\end{array}$ & $\begin{array}{l}30.3 \\
23.4 \\
46.3\end{array}$ & $\begin{array}{l}32.3 \\
25.2 \\
42.5\end{array}$ & $\begin{array}{l}34.0 \\
24.1 \\
41.9\end{array}$ & $\begin{array}{l}31.2 \\
24.3 \\
44.5\end{array}$ & $\begin{array}{l}32.3 \\
24.6 \\
43.1\end{array}$ & $\begin{array}{l}32.1 \\
24.7 \\
43.2\end{array}$ \\
\hline \multicolumn{7}{|l|}{ History of diabetes (\%) } \\
\hline $\begin{array}{l}\text { No } \\
\text { Yes }\end{array}$ & $\begin{array}{r}92.0 \\
8.0\end{array}$ & $\begin{array}{r}90.6 \\
9.4\end{array}$ & $\begin{array}{r}90.9 \\
9.1\end{array}$ & $\begin{array}{r}95.2 \\
4.8\end{array}$ & $\begin{array}{r}91.3 \\
8.7\end{array}$ & $\begin{array}{l}86.2 \\
13.8\end{array}$ \\
\hline Mean age at enrolment (s.d.) & $61.7(5.5)$ & $62.2(5.3)$ & $62.1(5.4)$ & $61.5(5.5)$ & $62.1(3.4)$ & $62.4(5.3)$ \\
\hline Mean BMI (s.d.) & $27.3(5.0)$ & $27.2(5.1)$ & $26.7(5.2)$ & $27.0(5.1)$ & $27.2(5.1)$ & $26.9(5.2)$ \\
\hline Median alcohol intake (g per day) (IQR) & $2.0(17.0)$ & $1.9(11.1)$ & $1.5(8.4)$ & $8.3(38.4)$ & $1.8(9.3)$ & $0.8(3.8)$ \\
\hline \multicolumn{7}{|l|}{ Mean dietary intake (s.d.) } \\
\hline $\begin{array}{l}\text { Total red meat (g per } 1000 \mathrm{kcal}) \\
\text { Processed meat (g per } 1000 \mathrm{kcal}) \\
\text { White meat (g per } 1000 \mathrm{kcal}) \\
\text { Fruit (MPED servings per } 1000 \mathrm{kcal}) \\
\text { Vegetable (MPED servings per } 1000 \mathrm{kcal}) \\
\text { Total energy intake (kcal per day) }\end{array}$ & $\begin{aligned} 39.8 & (23.2) \\
12.3 & (11.4) \\
25.0 & (20.8) \\
1.2 & (1.0) \\
1.1 & (0.4) \\
2075.6 & (954.3)\end{aligned}$ & $\begin{aligned} 35.7 & (20.7) \\
10.7 & (9.7) \\
34.4 & (23.9) \\
1.7 & (1.1) \\
2.1 & (0.6) \\
1826.6 & (767.6)\end{aligned}$ & $\begin{array}{c}26.1(19.1) \\
7.8(9.2) \\
40.2(29.9) \\
2.3(1.4) \\
3.7(1.4) \\
1593.6(652.9)\end{array}$ & $\begin{array}{c}35.3(21.3) \\
7.5(5.8) \\
27.9(23.6) \\
1.4(1.3) \\
1.6(0.8) \\
2044.5(967.2)\end{array}$ & $\begin{aligned} 35.9 & (20.3) \\
10.5 & (8.3) \\
35.0 & (25.0) \\
1.7 & (1.1) \\
2.2 & (0.9) \\
1827.3 & (763.9)\end{aligned}$ & $\begin{aligned} 30.5 & (24.1) \\
13.4 & (15.7) \\
35.4 & (26.5) \\
2.1 & (1.3) \\
2.9 & (1.7) \\
1659.7 & (697.1)\end{aligned}$ \\
\hline
\end{tabular}

\section{DISCUSSION}

In this large prospective US cohort, dietary intake of nitrite from animal sources, including, but not limited to processed meats, was associated with an increased risk of total RCC and the clear cell subtype, in particular. Total intake of nitrate and nitrite from processed meat sources was also positively associated with RCC risk. We found no associations for nitrate intake overall, or for nitrate or nitrite intake from plant sources and RCC risk. 
Table 2. Associations between intake of nitrate and nitrite and risk or renal cell carcinoma in the NIH-AARP Diet and Health Study ( $n=491841$ )

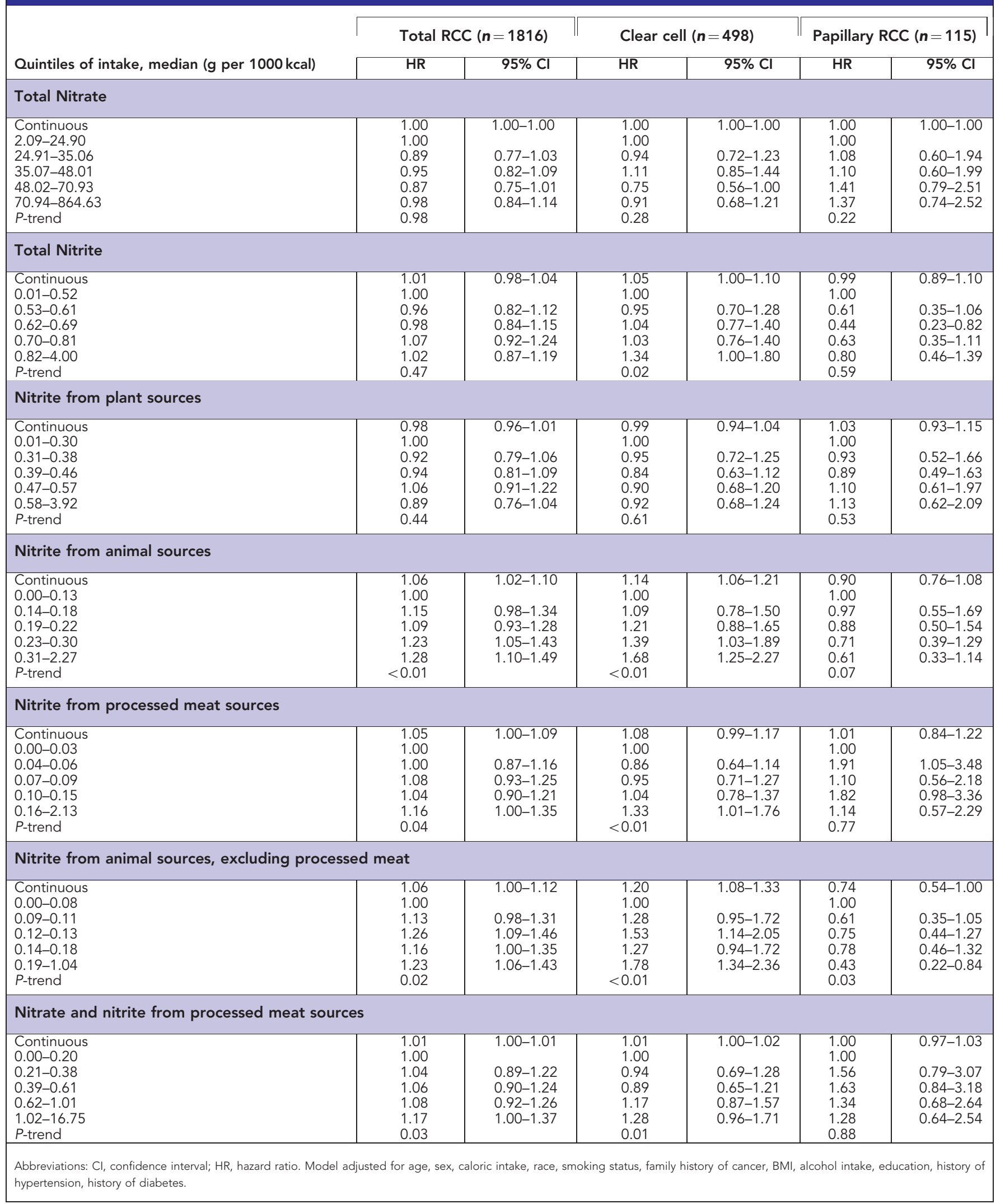

Results from previous studies examining associations between intake of animal products and risk of RCC have been inconsistent. Intake of processed meats, a major animal source of nitrate and nitrite, was associated with increased RCC risk in a few studies
(Hu et al, 2003; Brock et al, 2009), whereas other studies, including a large pooled analysis of 13 prospective studies (Alexander \& Cushing, 2009), observed no association (Chow et al, 1994; Wolk et al, 1996). Similarly, a positive association between red meat 
intake and risk of RCC was observed in some (Brock et al, 2009; Grieb et al, 2009; Daniel et al, 2012), but not all (Alexander \& Cushing, 2009) previous studies. A previous investigation within the NIH-AARP Diet and Health Study (Daniel et al, 2012) observed positive associations between red meat intake, as well as other components of meat: haem iron, heterocyclic amines and polycyclic aromatic hydrocarbons, and risk of total RCC and papillary cell RCC, but not the clear cell subtype. Our results suggest that the nitrate and nitrite content of animal products may also increase risk of RCC, particularly the clear cell subtype.

The previous investigation of meat intake and RCC within the NIH-AARP Diet and Health Study (Daniel et al, 2012) found no significant association between nitrate and nitrite intake from processed meat sources and RCC risk in a subset of participants that completed a detailed meat-cooking module. Risk of clear cell adenocarcinoma among participants in the highest quintile of nitrate and nitrite intake from processed meat (median $=0.29 \mathrm{mg}$ per day) was elevated, but not significantly different from those in the lowest quintile (median $=0.02 \mathrm{mg}$ per day) $(\mathrm{HR}=1.02,95 \%$ CI, 0.72-1.45). This is in contrast to our current analysis of the baseline dietary questionnaire using nitrate and nitrite values derived from the literature, which included 727 more total RCC cases and found a significant positive trend in risk of RCC and the clear cell subtype with increasing quintiles of nitrate and nitrite from processed meats. The previous findings of Daniel et al (2012) were based on nitrate and nitrite levels in 10 types of processed meats measured in 2004 (Sinha et al, 2005). In our analysis, intake estimates were based on historical literature values (Ward et al, 2003, 2006; Kilfoy et al, 2011), which were highly correlated (Spearman coefficient $=0.94$ ) with the 2004 measured values. As a result, risk estimates for both metrics were similar (results not shown). Therefore, the substantial increase in the number of cases analysed, which increased our power to detect associations for RCC overall and by subtype, is likely to explain our significant findings. Daniel et al. (2012) did not evaluate nitrate and nitrite from other dietary sources.

Nitrate can be reduced to nitrite by the oral bacterial flora and bacteria elsewhere within the digestive tract. In the acidic stomach, nitrite forms nitrosating agents that react with secondary amines or alkylamides to form NOCs, which have been found to produce tumours of the kidney in animal studies (IARC, 1998). Animal products, unlike plant sources of nitrate and nitrite, are a rich source of amines and amides. Therefore, intake of nitrate and nitrite from animal sources would be expected to lead to greater endogenous NOC exposure than intake from plant-based sources. Our findings of increased risk of RCC associated with nitrite from animal sources, including processed meat, supports the hypothesis that endogenous nitrosation may have a role in RCC risk, especially for the clear cell subtype. Previous case-control studies did not find an association between dietary nitrite and risk of RCC (Yuan et al, 1998; Ali et al, 2003; Ward et al, 2007). However, these studies were limited in that nitrite intake was not evaluated by food source, nor was RCC risk assessed by histological subtype. Our large prospective cohort study in which we evaluated nitrite intake by animal and plant food sources separately may have allowed us to observe effects that could be masked by considering only total dietary nitrite intake.

The associations we observed for the predominant clear cell subtype were largely consistent with what we observed for total RCC. We can only speculate as to why we observed positive associations between intakes of nitrite from animal sources and risk of clear cell, but not papillary subtypes, as the mechanisms through which nitrosation may affect risk of specific RCC subtypes are largely unexplored. To date, only Daniel et al (2012) investigated meat sources of dietary nitrate and nitrite and RCC risk by histological subtype. In this same study (Daniel et al, 2012), intakes of benzo(a)pyrene and 2-amino-1-methyl-6-phenyl- imidazo[4,5-b]pyridine was found to increase the risk of papillary RCC, but not clear cell RCC. This was the first study to investigate associations of meat compounds and RCC risk by histological subtype. It is also known that clear cell and papillary histological subtypes differ with respect to clinical features and genetic determinants (Cheng et al, 2009), which may indicate different etiologies. Contrary to our hypothesis, we observed an inverse association between nitrite from animal sources excluding processed meats and papillary RCC risk at the highest quintile of intake. A previous investigation of the New York University Women's Health Study cohort found a non-significant inverse association between serum nitrite and RCC risk (Ali et al, 2003), however this study did not examine papillary RCC specifically. Moreover, we used a strict subtype definition to avoid misclassification and, therefore, we had limited power for evaluation of risk for the much rarer, papillary subtype. Given the inconsistent associations we observed between different sources of nitrite intake and risk of papillary RCC and the relatively small number of cases $(n=115)$, we cannot rule out the possibility of a chance finding. Future follow-up of this finding is warranted.

We observed no association between intake of nitrate and nitrite from plant sources and RCC. Vitamin C and other antioxidants, which are found in high amounts in certain fruits and vegetables (Mirvish, 1994) inhibit endogenous nitrosation; thus, higher intake of nitrate or nitrite from plant sources may not result in substantial endogenous nitrosation (Bartsch et al, 1988). A casecontrol study of RCC in Iowa observed a positive association between nitrate in drinking water and RCC risk among individuals with vitamin $\mathrm{C}$ intake below the median $<132 \mathrm{mg}$ per day, but not among those with higher intakes (Ward et al, 2007). Although we observed differential effects of nitrate and nitrite from plant sources compared with animal sources, we did not observe interactions with vitamin C. However, we could only assess total vitamin $\mathrm{C}$ intake and not concurrent intake of vitamin $\mathrm{C}$ and nitrate and nitrite. Consistent with our findings, a cohort study of older women (Weyer et al, 2001) found no association between nitrate intake and RCC risk. Additionally, overall vegetable intake has shown no association (Chow et al, 1994; Rashidkhani et al, 2005) or an inverse association with RCC (Yuan et al, 1998; Hu et al, 2003).

There were several strengths and limitations of the current analysis. The large, prospective design and detailed assessment of nitrate and nitrite intake enabled us to investigate associations of nitrate and nitrite by food source and histological subtype of RCC, relationships that have not been previously examined. Although we had a sufficient number of cases to examine the two main histological variants it should be noted that slightly more than half of the total RCC cases lacked a more specific histomorphological determination. The proportion of RCC not otherwise specified in our study, however, is comparable to the Surveillance, Epidemiology, and End Results data (Lynch et al., 2007). In addition, it is difficult to completely isolate individual components, such as nitrate and nitrite, from their food sources. Therefore, it is possible that the associations we observed are due to other components of animal foods or processed meats. It is unlikely the associations we observed with clear-cell RCC can be explained by haem iron, heterocyclic amines or polycyclic aromatic hydrocarbons in meats, as these components were not associated with risk of clear-cell RCC in this cohort (Daniel et al, 2012) and correlations of these intakes with nitrate and nitrite intake were low (data not shown). Our assessment of nitrate and nitrite also did not capture cookingderived NOCs, which are formed particularly during the cooking of nitrite-cured meats. However, our analyses did examine nitrite intake from processed meats separately, which would be expected to correlate with preformed and cooking-derived NOCs. The selfreported nature of the FFQ and potential changes in an individual's diet over time leaves open the possibility of measurement error and 
subsequent exposure misclassification. However, our confidence in the validity of the FFQ is strengthened by the strong correlation reported for fruit and vegetable intake (Pearson coefficient $=0.72$ and 0.61 , for men and women, respectively) and factors related to meat intake, such as fat, cholesterol and to a lesser extent, protein, with a 24-h recall (Thompson et al, 2008). Our analyses were based on historic literature values, which may not fully reflect the change in nitrate and nitrite content of foods over time. However, as previously stated, we noted a high correlation between the literature-derived values and values based on 2004 measurements. We also conducted a sensitivity analysis excluding people in regions potentially exposed to high nitrate levels in their drinking water and observed results similar to our overall findings.

The results of our investigation suggest that intakes of nitrite from animal sources, including, but not limited to processed meats are associated with an increased risk of RCC, particularly the clear cell subtype. The variation in the association we observed by subtype suggests possible differences in RCC aetiology. Further evaluation of these findings in studies with classification of RCC by subtypes and information on source of dietary nitrate and nitrite intake is warranted.

\section{ACKNOWLEDGEMENTS}

This work was supported by the Intramural Research Program of the National Cancer Institute. Cancer incidence data from the Atlanta metropolitan area were collected by the Georgia Center for Cancer Statistics, Department of Epidemiology, Rollins School of Public Health, Emory University. Cancer incidence data from California were collected by the California Department of Health Services, Cancer Surveillance Section. Cancer incidence data from the Detroit metropolitan area were collected by the Michigan Cancer Surveillance Program, Community Health Administration, State of Michigan. The Florida cancer incidence data used in this report were collected by the Florida Cancer Data System (FCDC) under contract with the Florida Department of Health (FDOH). The views expressed herein are solely those of the authors and do not necessarily reflect those of the FCDC or FDOH. Cancer incidence data from Louisiana were collected by the Louisiana Tumor Registry, Louisiana State University Medical Center in New Orleans. Cancer incidence data from New Jersey were collected by the New Jersey State Cancer Registry, Cancer Epidemiology Services, New Jersey State Department of Health and Senior Services. Cancer incidence data from North Carolina were collected by the North Carolina Central Cancer Registry. Cancer incidence data from Pennsylvania were supplied by the Division of Health Statistics and Research, Pennsylvania Department of Health, Harrisburg, Pennsylvania. The Pennsylvania Department of Health specifically disclaims responsibility for any analyses, interpretations or conclusions. Cancer incidence data from Arizona were collected by the Arizona Cancer Registry, Division of Public Health Services, Arizona Department of Health Services. Cancer incidence data from Texas were collected by the Texas Cancer Registry, Cancer Epidemiology and Surveillance Branch, Texas Department of State Health Services. We are indebted to the participants of the NIH-AARP Diet and Health Study for their outstanding cooperation. We also thank Sigurd Hermansen and Kerry Grace Morrissey from Westat for study outcomes ascertainment and management and Leslie Carroll and Adam Risch at Information Management Services for data support and analysis. In memoriam of Dr Arthur Schatzkin, visionary investigator and founder of the NIH-AARP Diet and Health Study.

\section{CONFLICT OF INTEREST}

The authors declare no conflict of interest.

\section{REFERENCES}

Alexander DD, Cushing CA (2009) Quantitative assessment of red meat or processed meat consumption and kidney cancer. Cancer Detect Prev 32(5-6): 340-351.

Ali MA, Akhmedkhanov A, Zeleniuch-Jaquotte A, Toniolo P, Frenkel K, Huang X (2003) Reliability of serum iron, ferritin, nitrite, and association with risk of renal cancer in women. Cancer Detect Prev 27(2): 116-121.

Bartsch H, Ohshima H, Pignatelli B (1988) Inhibitors of endogenous nitrosation - mechanisms and implications in human cancer prevention. Mutat Res 202(2): 307-324.

Bogovski P, Bogovski S (1981) Animal species in which N-nitroso compounds induce cancer. Int J Cancer 27(4): 471-474.

Brock KE, Gridley G, Chiu BCH, Ershow AG, Lynch CF, Cantor KP (2009) Dietary fat and risk of renal cell carcinoma in the USA: a case-control study. Br J Nutr 101(8): 1228-1238.

Cheng L, Zhang SB, MacLennan GT, Lopez-Beltran A, Montironi R (2009) Molecular and cytogenetic insights into the pathogenesis, classification, differential diagnosis, and prognosis of renal epithelial neoplasms. Hum Pathol 40(1): 10-29.

Chilvers C, Inskip H, Caygill C, Bartholomew B, Fraser P, Hill M (1984) A survey of dietary nitrate in well-water users. Int J Epidemiol 13(3): 324-331.

Chow WH, Devesa SS, Warren JL, Fraumeni JF (1999) Rising incidence of renal cell cancer in the United States. JAMA 281(17): 1628-1631.

Chow WH, Dong LM, Devesa SS (2010) Epidemiology and risk factors for kidney cancer. Nat Rev Urol 7(5): 245-257.

Chow WH, Gridley G, McLaughlin JK, Mandel JS, Wacholder S, Blot WJ, Niwa S, Fraumeni JF (1994) Protein-intake and risk of renal-cell cancer. J Natl Cancer Inst 86(15): 1131-1139.

Daniel CR, Cross AJ, Graubard BI, Park Y, Ward MH, Rothman N, Hollenbeck AR, Chow WH, Sinha R (2012) Large prospective investigation of meat intake, related mutagens, and risk of renal cell carcinoma. Am J Clin Nutr 95(1): 155-162.

Eble JNSG, Epstein JI, Sesterhenn IA (2004) World Health Organization classification of tumours. Pathology and genetics of tumours of the urinary system and mail genital organs. IARC Press: Lyon, France.

Gangolli SD, Vandenbrandt PA, Feron VJ, Janzowsky C, Koeman JH, Speijers GJA, Spiegelhalder B, Walker R, Wishnok JS (1994) Nitrate, nitrite and N-nitroso compounds. Eur J Pharmacol Environ Toxicol Pharmacol Sect 292(1): 1-38.

Grieb SMD, Theis RP, Burr D, Benardot D, Siddiqui T, Asal NR (2009) Food groups and renal cell carcinoma: results from a case-control study. J Am Diet Assoc 109(4): 656-667.

Hard GC (1998) Mechanisms of chemically induced renal carcinogenesis in the laboratory rodent. Toxicol Pathol 26(1): 104-112.

Horner MJ, Ries LAG, Krapcho M, Neyman N, Aminou R, Howlader N, Altekruse SF, Feuer EJ, Huang L, Mariotto A, Miller BA, Lewis DR, Eisner MP, Stinchcomb DG, Edwards BK. (eds) (2009) SEER Cancer Statistics Review, 1975-2006. National Cancer Institute, Bethesda, MD. http:// seer.cancer.gov/csr/1975_2006/, based on November 2008 SEER data submission, posted to the SEER web site.

Hu JF, Mao Y, White K. Canadian Canc Registries E (2003) Diet and vitamin or mineral supplements and risk of renal cell carcinoma in Canada. Cancer Causes Control 14(8): 705-714.

IARC Monographs on the Evaluation of Carcinogenesis Risks to Humans (1998) Some N-nitroso compounds Vol. 17. International Agency for Research on Cancer: Lyon.

IARC Monographs on the Evaluation of Carcinogenesis Risks to Humans (2010) Ingested Nitrate and Nitrite, and Cyanobacterial Peptide Toxins Vol. 94. International Agency for Research on Cancer: Lyon.

Kilfoy BA, Zhang YW, Park Y, Holford TR, Schatzkin A, Hollenbeck A, Ward MH (2011) Dietary nitrate and nitrite and the risk of thyroid cancer in the NIH-AARP Diet and Health Study. Int J Cancer 129(1): 160-172.

Lynch CFWM, Davila JA, Platz CE (2007) Cancers of the kidney and renal pelvis. NIH publication no. 07-6215.

McKnight GM, Duncan CW, Leifert C, Golden MH (1999) Dietary nitrate in man: friend or foe? Br J Nutr 81(5): 349-358.

Michaud DSMD, Heransen S, Leitzmann M, Harlan LC, Kipnis V, Schatzkin A (2005) Comparison of cancer registry case ascertainment with SEER estimates and self-reporting in a subset of the NIH-AARP Diet and Health Study. J Registry Manag 32(2): 70-75. 
Mirvish SS (1994) Experimental evidence for inhibition of N-nitroso compound formation as a factor in the negative correlation between vitamin-C consumption and the incidence of certain cancers. Cancer Res 54(7): S1948-S1951.

Moller H, Landt J, Pedersen E, Jensen P, Autrup H, Jensen OM (1989) Endogenous nitrosation in relation to nitrate exposure from drinkingwater and diet in a danish rural-population. Cancer Res 49(11): $3117-3121$.

Moore LE, Wilson RT, Campleman SL (2005) Lifestyle factors, exposures, genetic susceptibility, and renal cell cancer risk: a review. Cancer Invest 23(3): 240-255.

Rashidkhani B, Lindblad P, Wolk A (2005) Fruits, vegetables and risk of renal cell carcinoma: A prospective study of Swedish women. Int $J$ Cancer 113(3): 451-455.

Schatzkin A, Subar AF, Thompson FE, Harlan LC, Tangrea J, Hollenbeck AR, Hurwitz PE, Coyle L, Schussler N, Michaud DS, Freedman LS, Brown CC, Midthune D, Kipnis V (2001) Design and serendipity in establishing a large cohort with wide dietary intake distributions - The National Institutes of Health-American Association of Retired Persons Diet and Health Study. Am J Epidemiol 154(12): 1119-1125.

Sinha R, Cross A, Curtin J, Zimmerman T, McNutt S, Risch A, Holden J (2005) Development of a food frequency questionnaire module and databases for compounds in cooked and processed meats. Mol Nutr Food Res 49(7): 648-655.

Thompson FE, Kipnis V, Midthune D, Freedman LS, Carroll RJ, Subar AF, Brown CC, Butcher MS, Mouw T, Leitzmann M, Schatzkin A (2008) Performance of a food-frequency questionnaire in the USNIH-AARP (National Institutes of Health-American Association of Retired Persons) Diet and Health Study. Public Health Nutr 11(2): 183-195.

Tricker AR (1997) N-nitroso compounds and man: sources of exposure, endogenous formation and occurrence in body fluids. Eur J Cancer Prev 6(3): $226-268$.
Ward MH, Cantor KP, Riley D, Merkle S, Lynch CF (2003) Nitrate in public water supplies and risk of bladder cancer. Epidemiology 14(2): 183-190.

Ward MH, Cerhan JR, Colt JS, Hartge P (2006) Risk of non-Hodgkin lymphoma and nitrate and nitrite from drinking water and diet. Epidemiology 17(4): 375-382.

Ward MH, deKok TM, Levallois P, Brender J, Gulis G, Nolan BT, VanDerslice J (2005) Workgroup report: drinking-water nitrate and health-recent findings and research needs. Environ Health Perspect 113(11): 1607-1614.

Ward MH, Rusiecki JA, Lynch CF, Cantor KP (2007) Nitrate in public water supplies and the risk of renal cell carcinoma. Cancer Causes Control 18(10): 1141-1151.

Weyer PJ, Cerhan JR, Kross BC, Hallberg GR, Kantamneni J, Breuer G, Jones MP, Zheng W, Lynch CF (2001) Municipal drinking water nitrate level and cancer risk in older women: the Iowa Women's Health Study. Epidemiology 12(3): 327-338.

Willett W (1998) Nutritional Epidemiology. Oxford University Press, New York.

World Health Organization (2000) International classification of diseases for oncology. 3rd edn. World Health Organization: Geneva, Switzerland.

Wolk A, Gridley G, Niwa S, Lindblad P, McCredie M, Mellemgaard A, Mandel JS, Wahrendorf J, McLaughlin JK, Adami HO (1996) International renal cell cancer study 7. Role of diet. Int J Cancer 65(1): 67-73.

Yuan JM, Gago-Dominguez M, Castelao JE, Hankin JH, Ross RK, Yu MC (1998) Cruciferous vegetables in relation to renal cell carcinoma. Int J Cancer 77(2): 211-216.

This work is published under the standard license to publish agreement. After 12 months the work will become freely available and the license terms will switch to a Creative Commons AttributionNonCommercial-Share Alike 3.0 Unported License. 